\title{
Detecção de inibidores de tripsina e atividade hemaglutinante em sementes de leguminosas arbóreas da amazônia
}

\author{
Larissa Ramos CHEVREUIL ${ }^{1}$, José Francisco de Carvalho GONÇALVES², Adriana BARIANI ${ }^{3}$, João Victor \\ Figueiredo Cardoso RODRIGUES ${ }^{4}$, Silvana Cristina PANDO 5
}

\begin{abstract}
RESUMO
Diferentes classes de proteínas são comuns em sementes de leguminosas, incluindo inibidores de tripsina e proteínas hemaglutinantes, as quais atuam sobre enzimas proteolíticas e sobre carboidratos da superfície celular, respectivamente. O objetivo deste trabalho foi quantificar, detectar e caracterizar parcialmente a ocorrência dessas proteínas em sementes de Tachigali plumbea, Sesbania exasperata e Ormosia costulata var. trifoliolata. Sementes das três espécies foram moídas e submetidas à extração salina $(\mathrm{NaCl} 0,15 \mathrm{M}-10 \%, \mathrm{p} / \mathrm{v})$. Os extratos totais obtidos foram utilizados para quantificar o conteúdo protéico, detectar a atividade residual da tripsina, a atividade hemaglutinante (AHE) e na obtenção do perfil protéico. A atividade residual da tripsina foi observada somente para T. plumbea e S. exasperata, cujos valores foram 4 e $19 \%$, respectivamente. A AHE foi detectada nos extratos das três espécies, sendo que os extratos totais de T. plumbea e $S$. exasperata, hemaglutinaram eritrócitos de rato, camundongo e hamster, enquanto que a espécie $O$. costulata hemaglutinou somente eritrócitos de hamster. O perfil protéico em SDS-PAGE revelou maior ocorrência de proteínas com massa molecular aparente de 10 a $30 \mathrm{kDa}$ para T. plumbea e $S$. exasperata, enquanto que para $O$. costulata prevaleceram bandas protéicas com massa molecular variando entre 20-25 $\mathrm{kDa}$. Conclui-se que os extratos totais de $O$. costulata e $S$. exasperata, pertencentes à subfamília Papilionoideae, apresentam menor conteúdo de inibidores de tripsina que T. plumbea (Caesalpinioideae) e, quanto à AHE, os resultados mostraram-se diferenciados, mesmo entre as espécies da mesma subfamília, tanto para a concentração mínima hemaglutinante quanto para a especificidade de interação com os eritrócitos.
\end{abstract}

PALAVRAS-CHAVE: Serinoproteinases, Sementes, Lectinas, Eritrócitos.

\section{Detection of trypsin inhibitors and hemagglutinating activity in tree leguminous seeds of amazonian}

\begin{abstract}
Different classes of proteins are common in Leguminosae seeds, including trypsin inhibitors and hemagglutinin proteins, which act on proteolytic enzymes and cell-surface carbohydrates, respectively. The aim of this work was to quantify, to detect and characterize partially these proteins in seeds of Tachigali plumbea, Sesbania exasperata and Ormosia costulata var. trifoliata. Seeds of the three species were powdered and submitted to an extraction with a saline solution $(\mathrm{NaCl} 0.15 \mathrm{M}-10 \%$, $\mathrm{p} / \mathrm{v})$. The resulting total extracts were used to quantify proteins content, detect the residual trypsin activity, hemagglutinating activity (AHE) and the proteic profile. Residual trypsin activity was observed only for T. plumbea and S. exasperata, which values were 4 and 19\% respectively. AHE was detected in extracts of all three species, total extracts of T. plumbea and S. exasperata hemagglutinated erythrocytes of rats, mice and hamsters, whereas $O$. costulata had this effect only on hamster erythrocytes. The proteic profile obtained by SDS-PAGE showed that T. plumbea and S. exasperata have a higher content of protein with an apparent molecular mass of $10-30 \mathrm{kDa}$, while $O$. costulata predominantly contains proteic bands with molecular masses varying between 20 to $25 \mathrm{kDa}$. It is concluded that total extracts of $O$. costulata and S. exasperata, species of the subfamily Papilionoideae, present less trypsin inhibitors than T. plumbea (Caesalpinioideae). AHE, both in form of minimum hemagglutinin concentration and the specified interaction with erythrocytes, differed even among species from the same subfamily.
\end{abstract}

KEYWORDS: Serine proteinases, Seeds, Lectins, Erythrocytes.

\footnotetext{
1 Engenheira Florestal, mestrado em Ciências de Florestas Tropicais -INPA. Laboratório de Fisiologia e Bioquímica Vegetal CPST/INPA, e-mail: Ichevreuil@inpa.gov.br

2 Pesquisador do Instituto Nacional de Pesquisas da Amazônia, Laboratório de Fisiologia e Bioquímica Vegetal CPST/INPA. Av. Ephigênio Sales, nº 2239. CEP: $69011-970$ - Caixa postal: 478. e-mail: jfc@inpa.gov.br

${ }^{3}$ Bolsista PCI-CNPq do Laboratório de Fisiologia e Bioquímica Vegetal da CPST/INPA. e-mail: bariani@inpa.gov.br

${ }^{4}$ Biólogo, mestrado em Botância - INPA. Laboratório de Fisiologia e Bioquímica Vegetal CPST/INPA e-mail: joaovictor@inpa.gov.br

5 Professora da Universidade Federal do Amazonas - UFAM. e-mail: scpando@ufam.edu.br
} 


\section{INTRODUÇÃO}

A família Fabaceae apresenta ampla distribuição biogeográfica e compreende um grande número de espécies economicamente importantes para a regiāo devido ao seu potencial madeireiro, à participação na fixação biológica de nitrogênio, além de serem consideradas importantes fontes de proteínas vegetais (Souza et al., 1994; Silva \& Souza, 2002; Ferreira et al., 2004).

As informações científicas sobre a composição química de sementes tropicais são úteis para a compreensão de sua fisiologia e obtenção de novos produtos a partir de reservas estocadas, como as proteínas, que corresponde em média, de 20 a 30\% do peso seco das sementes de leguminosas, embora existam exceções como as sementes de soja que podem chegar a 40\% (Vitale \& Bollini, 1995).

Dentre as várias classes funcionais das proteínas, encontradas nas sementes de leguminosas, destacam-se os inibidores proteolíticos e proteínas com propriedades hemaglutinantes, como por exemplo, as lectinas. Essas moléculas compreendem de 2 a $15 \%$ do conteúdo de proteínas totais, e são consideradas metabólitos importantes, podendo atuar no mecanismo de defesa contra insetos e patógenos, como fonte de aminoácidos sulfurados, na regulação de proteinases endógenas e como sinais de respostas às condiçôes ambientais (Chrispeels \& Raikhel, 1991; Bhattacharyya et al., 2006; Rameshwaram \& Nadimpalli, 2008; Wititsuwannakul et al, 2008; Konarev et al., 2008).

Os inibidores proteolíticos são proteínas que interagem específica e reversivelmente com diferentes enzimas proteolíticas, promovendo sua inibição por meio da competição com o substrato pelo sítio ativo da enzima (Richardson, 1991; Laskowski Jr. \& Qasim, 2000; Lingaraju \& Gowda, 2008). Desta forma, essas proteínas são classificadas de acordo com a sua especificidade de interação e podem afetar a atividade de serinoproteinases, cisteínoproteinases, proteinases aspárticas e metaloproteinases, as quais compreendem os grandes grupos de enzimas proteolíticas (Richardson, 1991; Tremacoldi \& Pascholati, 2004). As lectinas, por sua vez, são proteínas ou glicoproteínas que interagem especificamente com carboidratos de diferente natureza química, resultando na aglutinação de células animais e/ou vegetais e na precipitação de polissacarídeos, glicoproteínas ou glicolipídeos (Kennedy et al., 1995; Babosha, 2008).

Adicionalmente, essas duas classes de proteínas têm sido investigadas pelas suas funções em diversos processos biológicos, como por exemplo, para diagnósticos clínicos, na caracterização de glicoconjugados das superfícies celulares; na elucidação da estrutura de proteínas e carboidratos e em estudos da sua toxicidade sobre várias espécies de fungos fitopatogênicos e de insetos (Kennedy et al., 1995; Haq et al., 2004; Rawlings et al., 2004; Sharon, 2007).
Apesar do crescente interesse pelo isolamento e caracterização estrutural e funcional dessas proteínas, há poucos estudos com sementes de leguminosas arbóreas da Amazônia a despeito do potencial bioquímico das espécies desta família. Neste contexto, os objetivos deste trabalho foram quantificar e caracterizar parcialmente os inibidores de tripsina e proteínas com atividade hemaglutinante nas espécies: T. plumbea, S. exasperata e O. costulata, representantes de duas sub-famílias das leguminosas, visando contribuir para a obtenção de princípios bioativos de modo a agregar valor às potencialidades não-madeireiras da floresta amazônica.

\section{MATERIAL E MÉTODOS}

\section{MATERIAL VEGETAL}

Sementes maduras de Tachigali plumbea Ducke (Fabaceae, Caesalpinioideae) e Ormosia costulata var. trifoliolata (Miq.) Klein. (Fabaceae, Papilionoideae) foram coletadas na Estação Experimental de Silvicultura Tropical (EEST/INPA), localizada na Br-174 (Manaus-Boa Vista) - 2047'05'S e 60¹'51'W, e as sementes de Sesbania exasperata H. B. K. (Fabaceae, Papilionoideae) coletadas na várzea da Ilha da Marchantaria (Iranduba-Amazonas) - $3^{\circ} 16^{\prime} 7,60^{\prime \prime} \mathrm{S}$ e $59^{\circ} 59^{\prime} 57,86^{\prime \prime} \mathrm{W}$, a partir de matrizes selecionadas, localizadas às margens do rio Solimões, Manaus - AM. Todo material biológico coletado das matrizes referentes às espécies estudadas foi devidamente depositado e identificado no herbário do Instituto Nacional de Pesquisas da Amazônia (MCT - INPA).

\section{EXTRAÇÃO DE PROTEÍNAS}

As sementes inteiras foram secas à temperatura ambiente e trituradas até a obtenção de material pulverizado, posteriormente, as amostras foram homogeneizadas em solução salina $(\mathrm{NaCl} 0,15 \mathrm{M}, 10 \% \mathrm{p} / \mathrm{v})$ durante duas horas à temperatura ambiente $\left(26 \pm 3^{\circ} \mathrm{C}\right)$. A suspensão foi centrifugada a $5000 \mathrm{x}$ g durante 20 minutos a $4^{\circ} \mathrm{C}$ e, o sobrenadante, após diálise contra água destilada durante 48 horas, foi utilizado nas etapas posteriores.

\section{QUANTIFICAÇÃO DE PROTEÍNAS}

A concentração relativa de proteínas dos extratos foi estimada pelo método descrito por Bradford (1976), utilizando a BSA (albumina sérica bovina) como padrão. A leitura das absorbâncias foram obtidas por meio de um espectrofotômetro Spectrum UV-VIS SP-2000 UV.

\section{DETECÇÃO DE INIBIDOR DE TRIPSINA}

A determinação da concentração efetiva de solução de enzima foi realizada envolvendo a formação de uma acil-enzima estável e a liberação de $\rho$-nitrofenil, medido espectrofotometricamente, conforme descrito por Chase \& Shaw (1970) e Sampaio et al. (1984). 
A atividade inibitória foi realizada por meio de ensaio enzimático com tripsina bovina e o substrato DL-BAPNA (DL-benzoyl-arginina-paranitroanilida). O meio de préincubação consistiu em tampão Tris/ $\mathrm{HCl} 0,05 \mathrm{M}(\mathrm{pH}$ 8,0, tripsina bovina $50 \mu \mathrm{g}$, dissolvida em $\mathrm{HCl} 1 \mathrm{mM}$ ) e diferentes concentraçōes dos extratos totais, completando um volume final de $2 \mathrm{~mL}$. A pré-incubação foi efetuada durante 10 minutos a $37^{\circ} \mathrm{C}$. Após este período foi adicionado o substrato cromogênico DL-BAPNA $(0,5 \mathrm{mM})$, prosseguindo-se a incubação por mais 30 minutos a $37^{\circ} \mathrm{C}$.

A reação foi interrompida pela adição de ácido acético 30 $\%(\mathrm{v} / \mathrm{v})$ e a hidrólise do substrato pela enzima foi acompanhada fotometricamente a $410 \mathrm{~nm}$. O cálculo da atividade inibitória foi gerado a partir da determinação da atividade residual da tripsina no ensaio, de acordo com Erlanger et al. (1961).

\section{DETECÇÃO DE ATIVIDADE HEMAGLUTINANTE (AHE)}

Amostras de sangue de animais saudáveis (camundongo, hamster e rato branco), com idade de 2 a 3 meses, provenientes do biotério do INPA foram coletadas e homogeneizadas em solução anticoagulante $(2,05 \%$ de glicose; $0,8 \%$ de citrato de sódio e $0,42 \%$ de $\mathrm{NaCl}, \mathrm{pH} 6,1)$. Os eritrócitos foram lavados por quatro vezes com solução salina $(\mathrm{NaCl} 0,15 \mathrm{M}$, $10 \% \mathrm{p} / \mathrm{v}$ ) a $1000 \mathrm{xg}$ durante 10 minutos a $4^{\circ} \mathrm{C}$. O precipitado foi ressuspendido na mesma solução salina de modo a obter uma suspensão final de eritrócitos a $2 \%(\mathrm{v} / \mathrm{v})$.

O ensaio de hemaglutinação foi realizado em placas de microtitulação de 96 poços, os quais foram preenchidos com $50 \mu \mathrm{L}$ de solução salina, $50 \mu \mathrm{L}$ dos extratos totais e $50 \mu \mathrm{L}$ de suspensão de eritrócitos a 2\% (Pando et al., 2002).

\section{ELETROFORESE EM SDS-PAGE}

A análise do perfil protéico foi realizada segundo o método descrito por Laemmli (1970), modificado. O gel foi preparado a partir de uma solução estoque de acrilamida a $30 \%$ e de N-N'-metileno bis-acrilamida $0,8 \%$. Para o gel de concentração a $5 \%$, foi utilizado tampão Tris- $\mathrm{HCl} 0,125 \mathrm{M}$, $\mathrm{pH}$ 6,8, e para o gel de separação $12,5 \%$, tampão Tris- $\mathrm{HCl}$ $1 \mathrm{M}, \mathrm{pH} 8,8$, sendo acrescentado em ambos SDS 20\%, sendo a polimerização conseguida pela adição de TEMED e PSA $10 \%$.

As amostras $(30 \mu \mathrm{g})$ foram dissolvidas em tampão Tris$\mathrm{HCl}$ 0,08 M, pH 6,8, contendo 2\% de SDS, $10 \%$ de glicerol e $0,1 \%$ de azul de bromofenol. Como agente redutor foi utilizado o ditioteitrol (DTT) a de $0,1 \mathrm{M}$.

O gel foi corado com Coomassie Brilliant Blue em ácido acético $0,1 \%$, metanol e água deionizada na proporção de 1:4:5 (v/v/v) e descorados em solução de ácido acético glacial, metanol e água deionizada na proporção de 1:4:5 (v/v/v).

\section{RESULTADOS E DISCUSSÃO}

Os teores de proteínas variaram cerca de 2 a 9\% nas espécies estudadas e foram mais elevados nos extratos totais de $S$. exasperata e $O$. costulata, 5,1 e 8,9\%, respectivamente, espécies pertencentes à sub-família Papilionoideae (Figura 1). Enquanto que em T. plumbea o conteúdo protéico foi de $2,4 \%$. Estes resultados sugerem que as concentraçôes relativas dessas reservas podem variar entre as espécies e até entre espécies pertencentes à mesma família (Bewley, 1997, Corte et al., 2006). Adicionalmente, trabalhos realizados com sementes de leguminosas arbóreas demonstraram que as espécies Andira parviflora, Parkia pendula e Hymenea parviflora, apresentaram composição de reservas diferenciadas com teores protéicos bem mais elevados quando comparados aos teores obtidos nas espécies estudadas (Gonçalves et al., 2002).

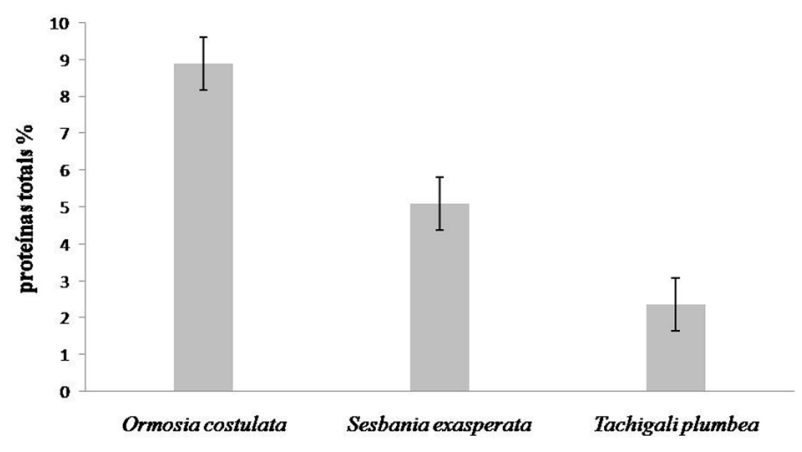

Figura 1 - Quantificação do teor de proteínas nos extratos totais de espécies de leguminosas arbóreas da Amazônia

A atividade inibitória dos extratos totais contra a tripsina bovina, uma serinoproteinase, foi detectada apenas nas espécies T. plumbea e S. exasperata (Tabela 1). No entanto, não se pode afirmar que no extrato protéico de $O$. costulata não há presença de inibidor de tripsina, uma vez que esta classe inclui outras enzimas proteolíticas como a quimotripsina e elastase, evidenciando, desta forma, a especificidade dos inibidores proteolíticos por determinadas enzimas proteolíticas. Essa especificidade de interação ocorre devido à presença de resíduos de aminoácidos no sítio reativo do inibidor que interagem específica e reversivelmente com os resíduos do sítio ativo da enzima alvo, permitindo a formação do complexo estável (Matheson et al., 1991; Bode \& Huber, 2000). Este fato tem sido demonstrado por alguns autores, como por exemplo, para as espécies Inga laurina e Lupinus albus, onde seus inibidores proteolíticos inibiram a atividade da tripsina, mas não da quimotripsina (Macedo et al., 2007; Scarafoni et al., 2008). 
Tabela 1 - Monitoramento da atividade enzimática na presença de, aproximadamente, 2,0 $\mu \mathrm{g}$ de proteínas dos extratos totais de espécies de leguminosas arbóreas da Amazônia.

\begin{tabular}{lc}
\hline Espécies & $\begin{array}{c}\text { Atividade residual da enzima (ARE) } \\
\%\end{array}$ \\
\hline Tachigali plumbea & 4 \\
Sesbania exasperata & 19 \\
Ormosia costulata & $\mathrm{Nd}$ \\
\hline
\end{tabular}

Nd: Não determinada.

De maneira mais específica, outros estudos com inibidores de proteinases têm evidenciado a presença dessas proteínas em várias espécies de leguminosas, incluindo: Delonix regia, Peltophorum dubium, Archidendron ellipticum (Pando et al., 2001; Macedo et al., 2003; Bhattacharyya et al., 2006). No que diz respeito a estudos realizados com espécies de leguminosas pertencentes à flora Amazônica, Calderon et al. (2001) demonstraram que extratos de Cassia brasselari, Cassia occidentalis, Dialium guianense, Inga rubiginosa, Inga umbratica, Inga velutina e Mimosa guillandinae, apresentaram tanto inibidores de quimotripsina como de tripsina, enquanto que Inga fagifolia e Cassia grandis inibiram apenas a atividade da tripsina.

Com relação à atividade hemaglutinante, os extratos totais de T. plumbea e $S$. exasperata, promoveram a hemaglutinação de eritrócitos de camundongo, hamster e rato branco. Por outro lado, o extrato de $O$. costulata hemaglutinou apenas eritrócitos de hamster (Tabela 2).

Em experimentos de caracterização da AHE é comum ocorrer diferenças de hemaglutinação em eritrócitos distintos, como demonstra Silva et al. (2001a), ao estudar a especificidade de hemaglutinação, de fraçôes purificadas de Bauhinia pentandra sobre eritrócitos de coelho, frango, pombo e de grupos sanguíneos humanos pertencentes ao sistema $\mathrm{ABO}$, onde constatou forte hemaglutinação em eritrócitos de coelho e fracamente em eritrócitos do grupo sanguíneo humano tipo A. As frações purificadas de sementes de Canavalia ensiformis e Dioclea grandiflora apresentaram especificidade somente por glóbulos vermelhos humanos (Melgarejo et al., 2005).

Os extratos totais de sementes de Peltogyne venosa hemaglutinaram eritrócitos de rato branco, camundongo e hamster, enquanto que os extratos de Cedrelinga catenaeformis não hemaglutinaram eritrócitos de camundongo (Bariani, 2007). Isto ocorre porque, apesar de as espécies pertencerem à mesma família, a especificidade por carboidratos diverge para cada espécie, o que está diretamente relacionado à composição estrutural das proteínas e composição química dos eritrócitos, cujo padrão de glicosilação diferencia-se de acordo com a espécie e isto, conseqüentemente, implica se o extrato vegetal promoverá ou não a hemaglutinação, dependendo da ocorrência de lectinas (Moreira et al., 1990; Chrispeels et al., 1991; Martinez et al., 2005).

Comparando os resultados obtidos para as espécies da mesma sub-família, observa-se que $S$. exasperata é capaz de promover hemaglutinação com concentrações protéicas inferiores a $O$. costulata (Tabela 2), sugerindo que apesar do alto teor protéico é possível que esta espécie contenha maior concentração de proteínas não pertencente à classe das lectinas (Tabela 2). Adicionalmente, muitas outras espécies leguminosas contêm proteínas que são claramente relatadas como lectinas, porém não são capazes de promover a hemaglutinação, uma vez que apresentam um único sítio de ligação a carboidratos, como as lectinas pertencentes à classe das merolectinas (Peumans \& van Damme, 1995).

Esses dados demonstram a possível presença de lectinas nos extratos protéicos das espécies estudadas, uma vez que essas proteínas apresentam especificidade de interação com diferentes eritrócitos, devido à sua capacidade de reconhecer os carboidratos presentes nas superfícies celulares (Sharon, 1993). Contudo, mesmo que o método de detecção da AHE seja o mais utilizado para a verificação da presença de lectinas, esse ensaio pode apresentar resultado falso se a lectina coexistir com inibidores, com substâncias presentes no sangue, glicoproteínas contendo ácido siálico, aminas heterocíclicas, carboidratos e certos íons metálicos, ou ainda, se os receptores para carboidratos presentes nas células não existirem em número suficiente ou estiverem inacessíveis (Toms, 1981). Nesse sentido, outros métodos devem ser utilizados em adição aos ensaios de hemaglutinação, como por exemplo, a precipitação de polissacarídeos ou glicoproteínas, bem como a submissão de extratos totais a métodos cromatográficos, visando o isolamento da proteína alvo (Kennedy et al., 1995).

Tabela 2 - Atividade hemaglutinante dos extratos totais de diferentes espécies de leguminosas sobre diferentes eritrócitos de animais.

\begin{tabular}{lccc}
\hline & \multicolumn{3}{c}{ Concentração mínima hemaglutinante } \\
\hline Eritrócitos & Tachigali plumbea $\left(\mu \mathrm{g} \mathrm{mL}^{-1}\right)$ & Sesbania exasperata $\left(\mu \mathrm{g} \mathrm{mL}^{-1}\right)$ & Ormosia costulata $\left(\mu \mathrm{g} \mathrm{mL}^{-1}\right)$ \\
Camundongo & 0,8 & 0,33 & $\mathrm{Nd}$ \\
Hamster & 0,8 & 0,33 & 12,33 \\
Rato Branco & 0,8 & 0,33 & $\mathrm{Nd}$ \\
\hline
\end{tabular}

Nd: Não determinada. 
O perfil protéico dos extratos totais das espécies em estudo foi similar na presença e na ausência de DTT, revelando maior ocorrência de proteínas com massas moleculares aparentes de $10 \mathrm{kDa}$ a $30 \mathrm{kDa}$ para T. plumbea e S. exasperata. Entretanto, para a $O$. costulata observou-se intensa coloração de proteínas com massas moleculares aparentes variando entre $20-25 \mathrm{kDa}$, estando as proteínas com massa molecular menor que $20 \mathrm{kDa}$ pouco evidentes (Figura 2).

Esses resultados sugerem a presença de lectinas, uma vez que a massa molecular das subunidades dessa classe de proteínas em leguminosas está em torno de $30 \mathrm{kDa}$, com a lectina completamente ativa, formando dímeros ou tetrâmeros com múltiplos sítios de ligação para carboidrato (Rüdiger, 1998). Adicionalmente, estudos têm comprovado que as lectinas isoladas de sementes de leguminosas como Baubinia pentandra, Crotalaria pallida, Talisia esculenta, Canavalia ensiformis e Dioclea grandiflora, apresentam a prevalência de bandas protéicas com massas moleculares variando de 20-40 kDa (Silva et al., 2001a; Rego et al., 2002; Freire et al., 2002; Melgarejo et al., 2005).

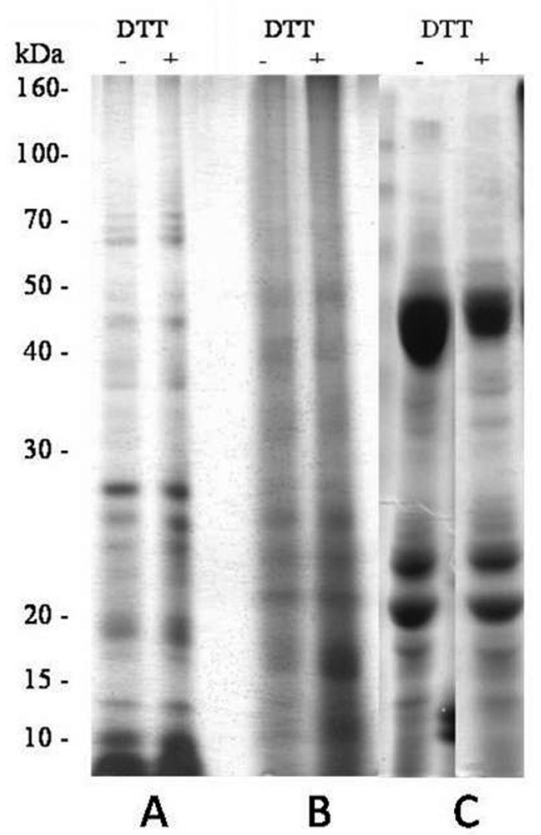

Figura 2 - Perfil eletroforético em SDS - PAGE (12,5\%, 90V, 17h). A: $20 \mu \mathrm{g}$ de extrato prote'ico se Sesbania exasperata; B: $36 \mu \mathrm{g}$ de extrato proteíco de Tachigali plumbea e C: $30 \mu \mathrm{g}$ de extrato protéico de Osmosia costulata var. trifoliolata, em condições não redutoras (-) e redutoras - DTT (+). Marcador de mass molecular: Bench Mark Protein Ladder (160kDa10kDa).kDa: Kilo Dalton.
A estimativa da massa molecular é um critério importante para classificar os inibidores de proteinases, onde os inibidores tipo Kunitz apresentam massas moleculares em torno de 18-22 $\mathrm{kDa}$ e os tipo Bowman-Birk em torno de $8-10 \mathrm{kDa}$ (Haq et al., 2004). Nesse sentido, a prevalência de bandas protéicas com massas moleculares variando de 10 a $25 \mathrm{kDa}$, corroboram com a presença de inibidores de serinoproteinases nos extratos totais, conforme encontrado paras as espécies Archidendron ellipticum e Entada scandens, onde os inibidores de tripsina tipo Kunitz apresentaram massa molecular de $20 \mathrm{kDa}$ e de $24 \mathrm{kDa}$ para Copaifera langsdorfii (Silva et al., 2001b; Bhattacharyya et al., 2006; Lingaraju \& Gowda, 2008).

Portanto, sementes de $T$. plumbea e $S$. exasperata, apesar dos baixos teores de proteínas encontrados, quando comparados com outras espécies de leguminosas, apresentaram altos conteúdos de inibidores de serinoproteinases e, provavelmente, proteínas da classe das lectinas nos extratos totais das três espécies estudadas, ressaltando usos potenciais dessas espécies em estudos futuros, como por exemplo, no tratamento de disfunçôes metabólicas associadas às enzimas proteolíticas e lectinas, tais como em casos de pancreatites, enfizemas, inflamações e certos cânceres, bem como verificar o envolvimento dessas proteínas no mecanismo de defesa das plantas, ao ataque de diferentes patógenos e predadores.

\section{AGRADECIMENTOS}

Os autores agradecem ao Ministério da Ciência e Tecnologia / Instituto Nacional de Pesquisas da Amazônia - INPA, ao biotério do INPA, ao Dr. Luiz Augusto Gomes de Souza (INPA-CPCA) e a toda a equipe do Laboratório de Fisiologia e Bioquímica Vegetal do INPA/LFBV. Os autores deste manuscrito também são gratos ao CNPq pelas concessōes das bolsas de Iniciação científica (IC), de mestrado (MS) e de produtividade $(\mathrm{PQ})$.

\section{BIBLIOGRAFIA CITADA}

Babosha, A.V. 2008. Induce lectins and plant resistance to pathogens and abiotic stress. Biochemistry, 73(7): 812-825.

Bariani, A. 2007. Propriedades bioquímicas e biológicas de proteinas de sementes de leguminosas arbóreas da Amazônia. Dissertação de Mestrado, Instituto Nacional de Pesquisas da Amazônia/ Fundação Universidade Federal do Amazonas, Manaus, Amazonas. 122p.

Bewley, J.D. 1997. Seed Germination and Dormancy. The Plant Cell, 9: 1055-1066.

Bhattacharyya, A.; Mazumdar, S.; Leighton, S.M. Babu, C.R. 2006. A Kunitz proteinase inhibitor from Archidendron ellipticum seeds: Purification, characterization, and kinetic properties. Phytochemistry, 67: 232-241. 
Bode, W.; Huber, R. 2000. Structural basis of the endoproteinase - protein inhibitor interation. Biochimica et Biophysica Acta, 1477: 241-252.

Bradford, M.M. 1976. A rapid and sensitive method for quantitation of microgram quantities of protein utilizing the principle of dye binding. Analytical Biochemistry ,72: 248-254.

Calderon, L.A.; Teles, R.C.L.; Leite, J.R.S.A.; Block, C. Jr.; AstolfiFilho, S.; Freitas, S.M. 2001. Serine protease inhibitors from Amazon Leguminosae seeds: purification and preliminary characterization of two chymotrypsin inhibitors from Inga umbratica. Protein and Peptide Letters, 8(6): 485-493.

Chase, T.; Shaw, E. 1970. Titration of trypsin, plasmin and thrombin with p-nitrophenyl-p-guanidinobenzoate $\mathrm{HCl}$. Methods in Enzymology, 19: 20 - 27.

Chrispeels, M.J.; Raikhel, N.V. 1991. Lectins, lectins genes, and their role in plant defense. The Plant Cell, 3: 1-9.

Corte, V.B.; Borges, E.E.L.; Pontes, C.A.; Leite, I.T.A.;Ventrella, M.C.; Mathias, A.A. 2006. Mobilização de reservas durante a germinação das sementes e crescimento das plântulas de Caesalpinia peltophoroides Benth. (Leguminosae-Caesalpinioideae). Revista Árvore, 30(6): 941-949.

Erlanger, B.F.; Kolowsky, N; Cohen, N. 1961. Preparation and properties of two new chromogenic substrates of trypsin. Archives of Biochemistry and Biophysics, 95: 271-278.

Ferreira, G.C.; Hopkins, M.J.G.; Secco, R.S. 2004. Contribuição ao conhecimento morfológico das espécies de leguminosae comercializadas no estado do Pará, como "angelim". Acta Amazonica 34(2): 219-232.

Freire, M.G.M.; Gomes, V.M.; Corsini, R.E.; Machado, O.L.T.; De Simone, S.G.; Novello, J.C.; Marangoni, S.; Macedo, M.L.R. 2002. Isolation and partial characterization of a novel lectin from Talisia esculenta seeds that interferes with fungal growth. Plant Physiology Biochemistry, 40: 61-68.

Gonçalves, J.F.C.; Fernandes, A.V.; Oliveira, A.F.M.; Rodrigues, L.F.R.; Marenco, R.A. 2002. Primary metabolism components of seeds from Brazilian Amazon tree species. Brazilian Journal of Plant Physiology, 14(2): 139-142.

Haq, S.K.; Atif S.M.; Khan, R.H. 2004. Protein proteinase inhibitor genes in combat against insects, pests, and pathogens: natural and engineered phytoprotection. Archives of Biochemistry and Biophysis, 431: 145-159.

Kennedy, J.F.; Palva, P.M.G.; Corella, M.T.S.; Cavalcanti, M.S.M.; Coelho, L.C.B.B. 1995. Lectins, versatile proteins of recognition: a review. Carbohudrate Polymers, 26: 219-230.

Konarev, A.V.; Lovegrove, A.; Shewry, P.R. 2008. Serine proteinase inhibitors in seeds of Cycas siamenis and other gymnosperms. Phytochemistry, 69 (13): 2482-2489.

Laemmli, U.K. 1970. Clevage of structural proteins during the assembly of the head of bacteriophage T4. Nature, 227: 680685 .

Laskowski Jr., M.; Qasim, M.A. 2000. What can the structures of enzyme-inhibitor complexes tell us about the structures of enzyme substrate complexes? Biochimica et Biophysica Acta, 1477: 324-337.
Lingaraju, M.H.; Gowda, L.R. 2008. A Kunitz trypsin inhibitor of Entada scandens seeds: Another member with single disulfite bridge. Biochimica et Biophysica Acta, 1784:850-855.

Macedo, M.L.; Freire, M.G.M.; Cabrini, E.C.; Toyama, M.H.; Novello, J.C.; Marangoni, S. 2003. A trypsin inhibitor from Peltophorum dubium seeds active against pest proteases and its effect on the survival of Anagasta kuehniella (Lepidóptera: Pyralidae). Biochimica et Biophysica Acta, 1621: 170-182.

Macedo, M.L.; Garcia, V.A.; Freire, M.G.; Richardson, M. 2007. Characterization of a Kunitz trypsin inhibitor with a single disulfite bridge from seeds of Inga laurina (SW.) Wild. Phytochemistry, 68: 1104-1111.

Martinez, C.R.; Netto, A.M.; Figueiredo, M.V.B.; Cavada, B.S.; Lima, J.L. 2005. Kinetic sedimentation of Rhizobium-aggregates produces by leguminous lectins. World Journal of Microbiologye Biotechnology, 21(1): 75-82.

Matheson, N.R.; van Halbeek, H.; Travis, J. 1991. Evidence for a tetrahedral intermediate complex during serpin-proteinase interactions. The Journal Biology Chemistry, 266(25): 1348913491.

Melgarejo, L.M.; Vega, N.; Pérez, G. 2005. Isolation and characterization of novel lectins from Canavalia ensiformis DC and Dioclea grandilfora Mart. ex Benth. Seeds. Brazilian Journal of Plant Physiology, 17(3): 315-324.

Moreira, R.A.; Cavada, B.S.; Oliveira, J.T.A. de; Ainouz, I.L. 1990. Plant lectins. Proceeding of the first Brazilian congress on proteins - COBRAP, 90: 73-96.

Pando, S.C., Macedo, M.L.R.; Freire, M.G.M.; Toyama, M.H.; Novello, J.C.; Marangoni, S. 2002. Journal of Protein Chemistry, 21(4): 279-285.

Pando, S.C.; Oliva, M.L.V.; Sampaio, C.A.M.; Ciero, L.D.; Novello, J.C.; Marangoni, S. 2001. Primary sequence determination of a Kunitz inhibitor isolated from Delonix regia seeds. Phytochemistry, 57: 625-631.

Peumans, W.J.; van Damme, E.J.M. 1995. Lectins as plant defense proteins. Plant Physiology, 109: 347-352.

Rameshwaram, N.R.; Nadimpalli, S.K. 2008. An efficient method for the purification and quantification of a galactose-specific lectin from vegetative tissues of Dolichos lablab. Journal of Chromatography B, 861: 209-217.

Rawlings, N.D.; Tolle, D.P.; Barret, A.J. 2004. Evolutionary families of peptidase inhibitors. Biochemical Journal, 378: 705-716.

Rego, E.J.L.; Carvalho, D.D.; Marangoni, S.; Oliveira, B.; Novello, J.C. 2002. Lectins from seeds of Crotalaria pallida (smooth rattlebox). Phytochemistry, 60: 441-446.

Richardson, M. 1991. Seed storage proteins: the enzyme inhibitors. Methods in Plant Biochemistry, 5:259-305.

Rüdiger, H. 1998. Plant lectins - more than just tools for glycoscientists: occurrence, structure and possible functions of plant lectins. Acta Anatomica, 161: 130-152.

Sampaio, C.A.M.; Sampaio, M.U.; Prado, E.S. 1984. Active titration of horse urinnery kallikrein. Hoppe-Seyler's Zeitschrift für Physiologische Chemie., 365: 297 - 302. 
Scarafoni, A.; Consonni, A.; Galbusera, V.; Negri, A.; Tedeschi, G.; Rasmussen, P.; Magni, C.; Duranti, M. 2008. Identification and characterization of a Bowman-Birk inhibitor active towards trypsin but not chymotripsin in Lupinus albus seeds. Phytochemistry, 69:1820-1825.

Sharon, N. 1993. Lectin - carbohydrate complexes of plants and animals: na atomic view. Trends in Biochemical Sciences, 18: 221-226.

Sharon, N. 2007. Lectins: Carbohydrate-specific reagents and biological recognition molecules. The Journal of Biological Chemistry, 282 (5): 2753-2764.

Silva, A.L.C.; Horta, A.C.G.; Moreira, R.A. 2001a. Isolation and parcial characterization of a lectin from Bauhinia pentandra (Bong) Vog. ex. Steua. Revista Brasileira de Fisiologia Vegetal, 13(3): 262-269.

Silva, J.A.; Macedo, M.L.R.; Novello, J.C.; Marangoni, S. 2001 b. Biochemical characterization and $\mathrm{N}$-terminal sequences of two new trypsin inhibitors from Copaifera langsdorffli seeds. Journal of Protein Chemistry, 20 (1): 1-7.

Silva, M.F.; Souza, L.A.G. 2002. Levantamento das leguminosas do arquipélago das Anavilhanas, baixo rio Negro, Amazonas. Boletim Paraense Emílio Goeldi, série Botânica, 18(1): 3-35.
Souza, L.A.G.; Silva, M.F.; Moreira, F.W. 1994. Capacidade de nodulação de cem leguminosas da Amazônia. Acta Amazonica, 24(1/2): 9-18.

Toms, G.C. 1981. Lectins in Leguminosae. In: Polhill, R.M.; Raven, P.H. (Eds). Advances in Legume Systematics. Royal Botanic Gardens, Kew, 2: 561-577.

Tremacoldi, C.R.; Pascholati, S.F. 2004. Inibidor de tripsina em raízes de Eucalyptus urophylla. Fitopatologia Brasileira, 29(2): 135-140.

Vitale, A.; Bollini, R. 1995. Legume Storage Proteins. In: Kigel, J.; Galili, G. (Eds). Seed Development and Germination. Marcel Dekker, New York. p. 73-102.

Wititsuwannakul, R.; Pasitkul, P.; Kanokwiroon, K.; Wititsuwannakul, D. 2008. A role for a Hevea latex lectin-like protein in mediating rubber particle aggregation and latex coagulation. Phytochemisty, 69: $339-347$.

Recebido em 26/08/2008

Aceito em 26/10/2008 
